\title{
Particle morphology and size distribution of plasma processed aluminium powder
}

\author{
P V ANANTHAPADMANABHAN, K P SREEKUMAR, \\ N VENKATRAMANI, R KAMESWARAN*, C C DIAS* and \\ S C MISHRA ${ }^{+}$ \\ Laser and Plasma Technology Division, *Analytical Chemistry Division, Bhabha Atomic \\ Research Centre, Bombay 400085 , India \\ ${ }^{+}$Department of Metallurgical Engineering, Regional Engineering College, Rourkela 769008 , \\ India
}

\begin{abstract}
Commercially available aluminium powder has been processed in a thermal plasma jet. The processed powder has been characterized by scanning electron microscopy (SEM) for particle size and morphology. Particle size distribution has been determined by laser scattering technique. Results show that, in contrast to the irregular shapes of the particles of the raw material, majority of the processed powder particles bear spherical or near-spherical morphology. The spherical morphology without sharp edges and corners and particle size distribution in a narrow range ensures free flow of the powder through the powder feed lines. and better spray efficiency, making it ideal for thermal spray applications.
\end{abstract}

Keywords. Plasma processing; spheroidization; spray quality powder.

\section{Introduction}

Aluminium powder is extensively used in thermal spray applications for preparing metallic and alloy coatings. The metal powder used for thermal spray applications has to meet several specifications. The ability of the powder to freely flow, particle shape, size and distribution are important factors that need to be controlled to achieve the desired coating properties (Sreekumar et al 1991). These powder characteristics depend on the method of preparation of the powder.

Thermal spray-quality powders are manufactured by many techniques (Meddings et al 1961; Ito et al 1991). The primary manufacturing methods for ceramic powders used for spray applications involve melting, crushing and sieving. Metals and alloys are usually produced by several techniques including atomization, reduction of cxides and electrolytic deposition. Plasma processing can also be used to produce spray-quality powders (Ananthapadmanabhan et al 1995). In fact, plasma processing can be considered as a variation of the atomization technique, which consists in striking a molten metal stream with jets of gas, air or water and fragmenting it into minute droplets, which solidify into individual powder particles. Plasma processing combines both the melting and atomizing processes in one single step. Liquid fragmentation is accomplished by the kinetic energy of the atomizing medium, typically nitrogen, argon or air. The resulting particles tend to be smooth and spherical. The application of thermal plasmas to powder processing has many distinct advantages: (i) the temperature of the plasma is higher than the melting point of metals and ceramics and hence can be applied to process metal, alloy or ceramic powder, (ii) the processed powders have

\footnotetext{
${ }^{+}$Paper presented at the poster session of MRSI AGM VI, Kharagpur, 1995
} 
spherical morphology and excellent flow characteristics, (iii) the residence time in the plasma being very low, the impurities in the product is within acceptable limits and (iv) the method is highly versatile and applicable to all metals and ceramics.

The present paper deals with preparation and characterization of plasma processed aluminium powder.

\section{Experimental}

A $40 \mathrm{~kW}$ atmospheric plasma spray torch-based chemical reactor, set up in our division for materials processing studies was used to process commercially available aluminium powder. The schematic representation of the plasma chemical reactor is shown in figure 1 . The dc plasma torch is mounted on a water-cooled reaction quench chamber made of stainless steel ( $60 \mathrm{~mm}$ diameter and $600 \mathrm{~mm}$ long). The plasma torch consists of a conical thoriated tungsten cathode and a copper anode made in the form of a nozzle. Both the electrodes are intensely water-cooled. The set-up also consists of a dc power supply ( $80 \mathrm{~V}, 600$ ampere), powder feeder, water and gas lines and control console system. The arc is initiated by striking a high intensity current between the electrodes. The plasma gas, usually a mixture of argon and nitrogen injected in the inter electrode region abstracts heat from the electric arc and issues out of the nozzle as a high temperature high velocity plasma jet.

Aluminium metal powder, stored in a powder feeder was fed into the plasma stream through a side orfice in the anode assembly of the torch using argon as the carrier gas. As the metal particles enter the plasma jet, they are heated to the melting point and the molten drops re-solidify and get collected in a polished flat-bottomed stainless steel vessel placed inside the collector assembly. The distance between the torch nozzle and the collection vessel was suitably adjusted. Typical operating parameters are given in table 1 .

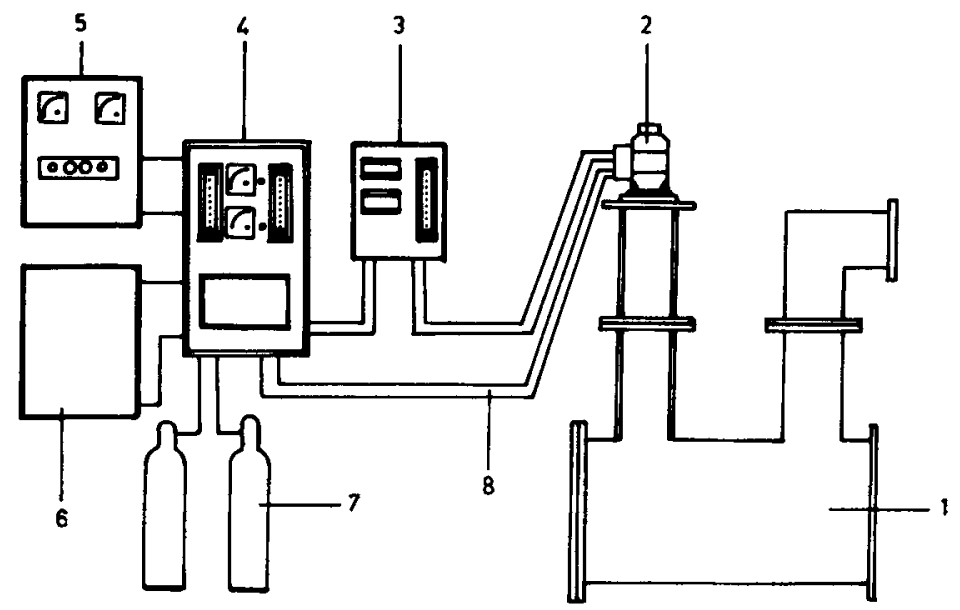

Figure 1. Schematic representation of plasma chemical reactor. 1. Reactor assembly, 2. plasma torch, 3. powder feeder, 4. control console, 5. power supply, 6. cooling water, 7. plasma gas and 8 . supply lines. 
Table 1. Typical operating parameter.

\begin{tabular}{lcr}
\hline Power input & (kW) & 12 \\
Plasma gas Ar & (LPM) & 20 \\
Secondary gas $\mathrm{N}_{2}$ & (LPM) & 02 \\
Carrier gas Ar & (LPM) & 08 \\
Flight distance & (mm) & 300 \\
\hline
\end{tabular}

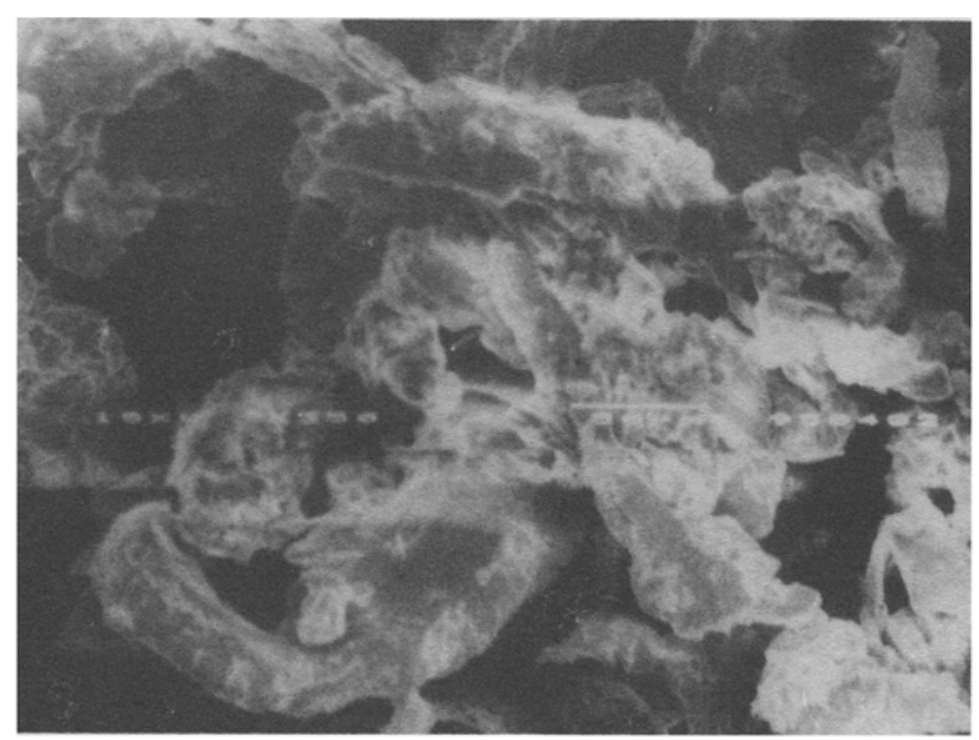

Figure 2. SEM image of aluminium powder.

The processed powder was characterized by X-ray powder diffraction technique for phase composition. Particle morphology and size were determined by scanning electron microscopy (SEM). Particle size distribution was determined by laser scattering technique using Malvern Particle Sizer, model 3600 E.

\section{Results and discussion}

Phase composition of the processed powder, as ascertained by X-ray diffraction shows that it consists of aluminium metal. Figure 2 shows the electron micrograph of the raw aluminium powder. It is evident from the figure that the particles have irregular shapes with sharp edges. The wide range in particle size distribution can also be seen. The SEM images of aluminium powder processed at 10 and $12 \mathrm{~kW}$ power levels are shown in figures $3 a$ and $b$ respectively. The micrographs show that majority of the processed particles have spherical or near-spherical morphology. Particle agglomeration is also evident from the figures. Ideally, one expects all the particles to have spherical morphology. However, all the particles entering the plasma stream are not subject to the same thermal treatment (Ananthapadmanabhan et al 1994). This is due to a number of factors, the most important among them being, the spread in the particle size of 

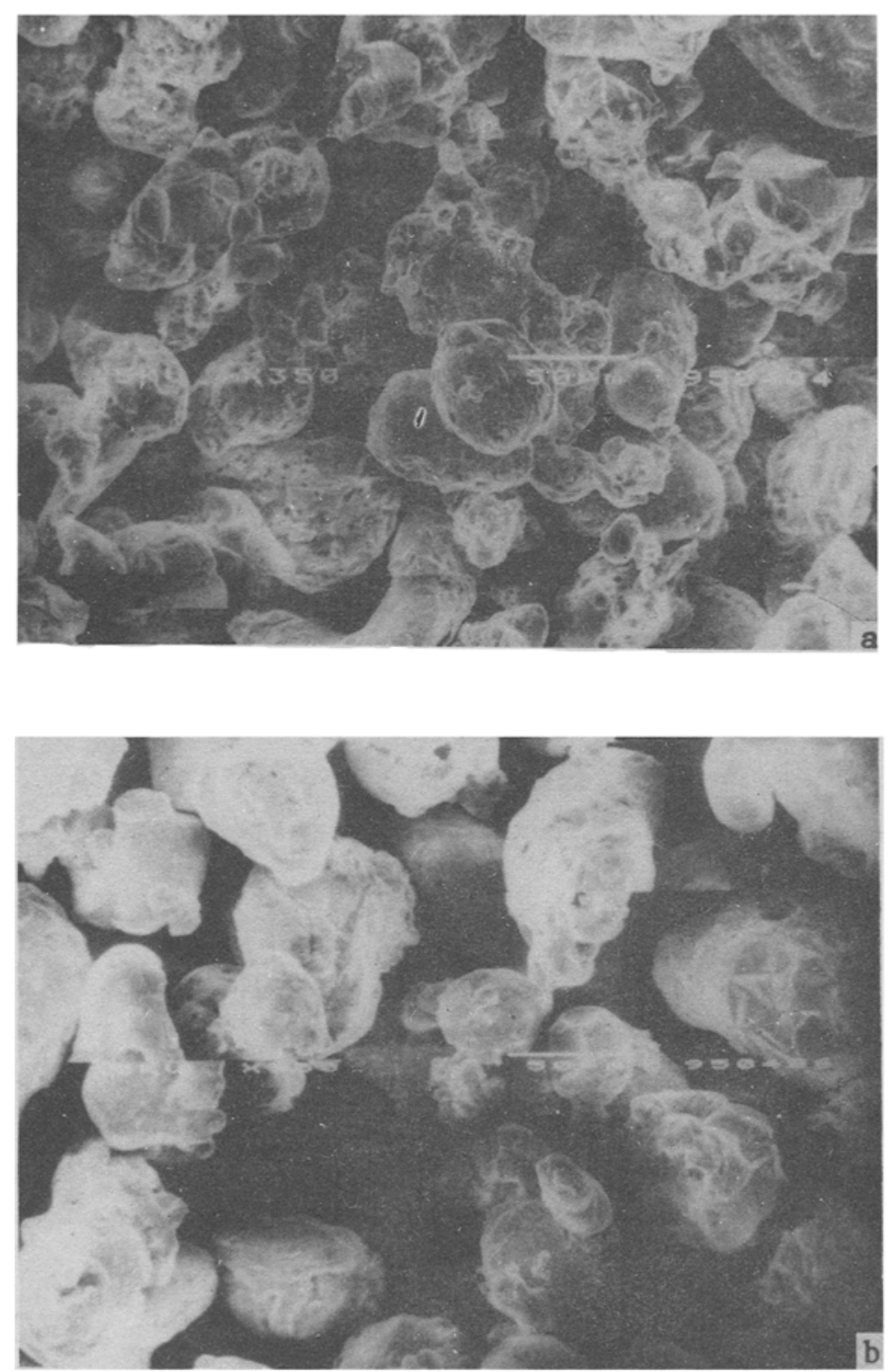

Figure 3. SEM images of plasma processed aluminium powder a. $10 \mathrm{~kW}$ and b. $12 \mathrm{~kW}$.

the feed material, temperature and enthalpy of the plasma and also the subsequent interaction of the molten and partially molten droplets in the plasma stream. Since the residence time of the particles in the plasma is of the order of a few tens of milliseconds, larger particles are only partially melted resulting in oval or near-spherical particles. Interaction of partially molten particles also lead to oval particles. Partial melting also results in surface porosity, as is evident from the micrographs.

Particle size distribution of aluminium powder processed at 10 and $12 \mathrm{~kW}$ levels are shown in figures $4 \mathrm{a}$ and $\mathrm{b}$ respectively. The particle size distribution shows that about 


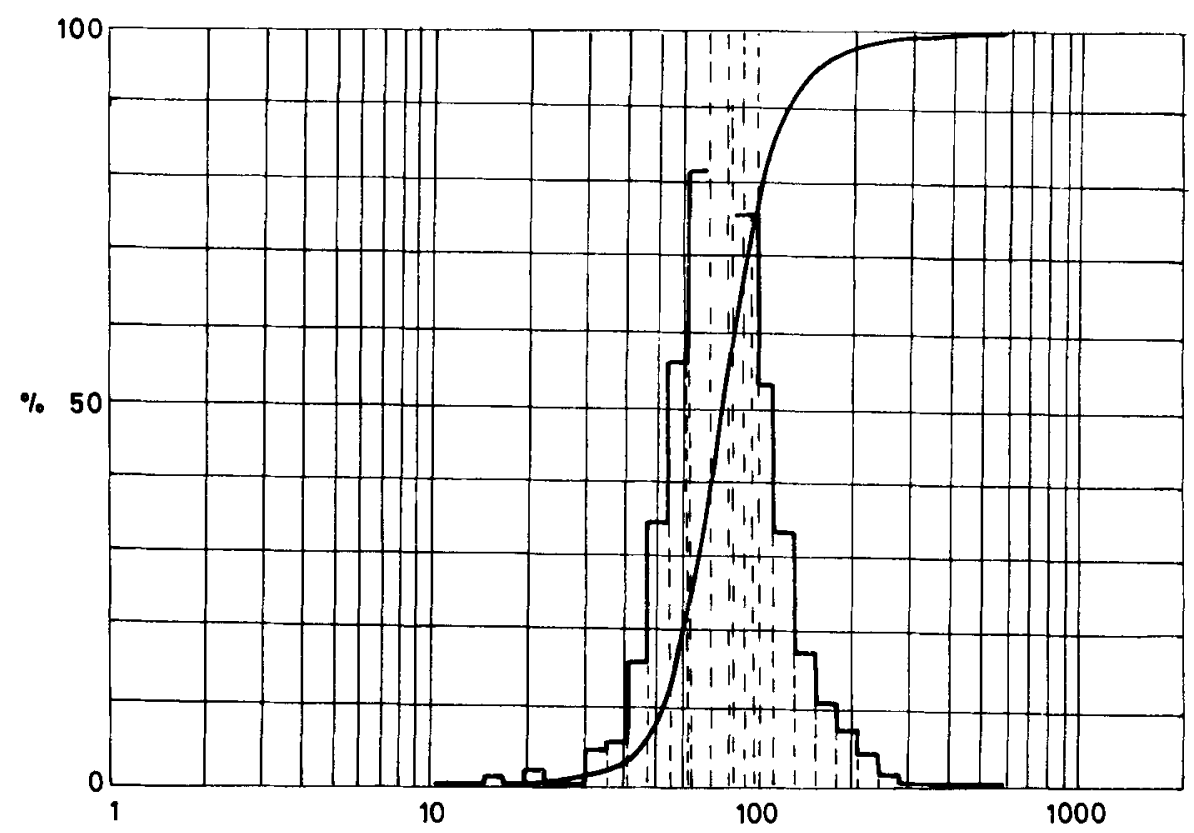

PARTICLE SIZE $(\mu \mathrm{m})$ a

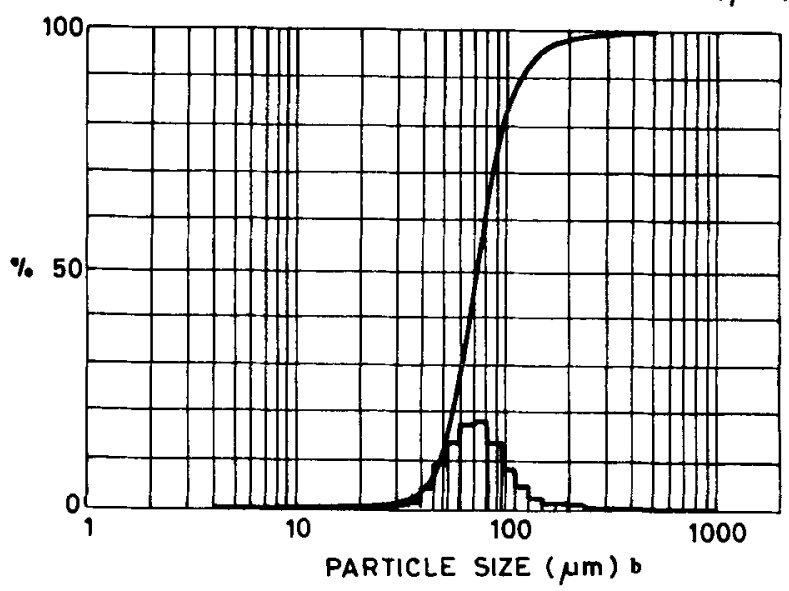

Figure 4. Particle size distributions of plasma processed aluminium powder a. $10 \mathrm{~kW}$ and b. $12 \mathrm{~kW}$.

$50 \%$ of the particles, processed at $10 \mathrm{~kW}$ power, lie between 20 and $75 \mu$. About $30 \%$ of the particles lie in the $75-100 \mu$ range. In the case of powder processed at $12 \mathrm{~kW}$, it is seen that about $50 \%$ of the particles lie in the $20-70 \mu$ range and $35 \%$ lie in the $70-100 \mu$ range. It is also seen that about $60-65 \%$ of the particles lie in the $50-90 \mu$ range. It was also observed that at a high input power to the plasma torch ( $12 \mathrm{~kW}$ and above), a substantial amount of the aluminium powder vaporized and condensed as submicron particles on the walls of the reaction chamber.

The near-spherical morphology of the particles, with more than $60 \%$ of the particles distributed over a narrow range show that plasma processed powders are ideally suited for thermal spray applications. The near spherical morphology without sharp edges 
and corners ensure free flow of the powder through the powder feed lines. Further, since the processing involves melting and quenching of the particles, internal porosity in the powder particles is practically absent resulting in high density powder. All these factors ensure high spray efficiency and better coating properties.

\section{Conclusion}

Plasma processing of aluminium powders results in dense free-flowing particles, which have a near-spherical or spherical morphology. The morphology of the processed powder is influenced by a number of parameters including the power input to the torch and the spread in the particle size of the raw material. Particle size distribution studies in the processed powder show that quite a good percentage of the particles are distributed in narrow range, which is ideal for thermal spray applications.

\section{Acknowledgements}

The authors are grateful to Dr B A Dasannacharya, Director, MDT Group and Shri U K Chatterjee, Head, L\&PT Division, BARC for their encouragement and support. The authors are also thankful to Shri B R Ambekar, Applied Chemistry Division, BARC, for his help in X-ray diffraction work.

\section{References}

Ananthapadmanabhan P V, Sreekumar K P, Veeramani Iyer K and Venkatramani N 1994 Mater. Chem. \& Phys. 3815

Ananthapadmanabhan P V, Sreekumar K P, Ravindran P V, Venkatramani N and Mishra S C 1995 Int. Ther. Spray. Conf., ITSC 95, Kode Japan

Ito H, Umakoshi M, Nakamura R, Yokoyama T, Urayama K and Kato M 1991 Proc. fourth nat. ther. conf., Pittsburgh, USA (Ohio: ASM International) p. 405

Meddings B, Kunda M and Mackiv V N 1961 Powder metallurgy (ed.) W Leszynski (Interscience) p. 775

Sreekumar K P, Karthikeyan J, Ananthapadmanabhan P V, Venkatramani N and Chatterjee U K 1991 BARC report No. 1551, L \& IS Dn., BARC, Bombay 